\title{
SVAT MODELLING IN SUPPORT TO FLOOD RISK ASSESSMENT IN BULGARIA
}

\author{
Julia S. Stoyanova, Christo G. Georgiev \\ National Institute of Meteorology and Hydrology, Bulgarian Academy of Sciences \\ Tsarigradsko chaussee 66, Bulgaria, julia.stoyanova@meteo.bq
}

(Dated: 26 August 2011)

\section{INTRODUCTION}

Soil moisture (SM), terrestrial vegetation and atmospheric flows are parts of a complex interacting system characterised by the presence of many feedback mechanisms between the various components (Baudena et al., 2008) that is responsible for occurrence of atmosphere phenomena and their extremes on a synoptic and a dynamic base. It is recognized that the SM and its gradient play a significant role in convection initiation under certain synoptic types. Le Lay and Saulnier (2007) pointed out the importance of the initial SM on the accuracy of the simulated flash-flood event, which occurred in September 2002 in the Gard region in France at strong large scale thermodynamic forcing (Santurette and Georgiev, 2005). They showed that not only the rainfall but also the initial soil water content controlled the flash-flood.

A way to account for initial SM at a regional scale is running a soil-vegetation-atmosphere transfer (SVAT) model. This approach is used in our work to evaluate the status of the land surface moistening conditions as additional to the numerical weather prediction (NWP) information for analyses of soil overmoistening and flood risk

The first aim of this paper is to present: (i) The developed at the National Institute of Meteorology and Hydrology /NIMH/ Bulgarian SVAT scheme and on this basis, the numerical assessments of volumetric SM content at a site-scale; (ii) A threshold scheme for evaluation of soil moisture availability for vegetation cover over Bulgaria. The second aim is to analyse the role of land surface moistening as an additional to the troposphere thermodynamic conditions factor in convection initiation/development. The usefulness of SVAT soil moisture products in support to operational forecasts of convective weather events as well as flood risk diagnoses is considered.

\section{SOIL-VEGETATION-ATMOSPHERE MODEL AND SOIL MOISTURE OUTPUT}

In general, soil moisture maintains control over the land-atmosphere interaction, which can affect the features of deep convection through the regional energy cycle and water cycle. The connection between soil and atmosphere processes is established through the energy balance conservation according to the first law of thermodynamics.

SVAT Model description. A numerical (1D vertical) SVAT model for quantitative description of massand energy- exchange processes at vegetated land surface has been developed at NIMH of Bulgaria (Stoyanova and Georgiev, 2007; 2011) and introduced as 'SVAT_bg'. As input parameters, the model uses information from synopticand agro- networks. In 2010 'SVAT_bg' was introduced in daily operational work at NIMH for early warning and multifunctional risk assessment of natural hazards on vegetated land surface. In the current study this coupled model is parameterised for perennial grass cover /Lucerne/. The model algorithm accounts for regional site-specific physical climate at the locations of synoptic and soil moisture gravimetric observations. 'SVAT_bg' numerical scheme includes following procedures: solving the surface energy balance (eq.1) at a thermodynamic equilibrium surface temperature state; closing the surface water budget (eq.2) parallel to the coupling between the two equations:

$$
\begin{aligned}
& \mathrm{R}_{\mathrm{n}}=\mathrm{LE} \uparrow+\mathrm{H} \uparrow+\mathrm{S} \downarrow \\
& \Delta \mathrm{W}=\text { Precip -Evap }
\end{aligned}
$$

Where, $R_{n}$ is the net radiation of the closed canopy, LE and $\mathrm{H}$ are the fluxes of latent and sensible heat leaving the surface and $\mathrm{S}$ the heat flux entering the soil. $\Delta \mathrm{W}$ is the evolution of the moisture reservoirs. Equations are solved iteratively at a daily time step for the topsoil surface adopting a bucket approach at non-limited and restricted evapotranspiration regimes. Evapotranspiration required for solving these equations in the root zone is modelled using a simple water vapour diffusion equation with fractional relative humidity as the driving gradient. Calculations are referred for the not frozen season and negative air temperatures.

Indexes of plant ecosystems status and threshold schemes as information sources of extreme weather events. Ecosystem dynamics cannot be considered just as a passive boundary condition to atmospheric flows, but rather they are one of the leading actyors on stage (e.g. Claussen, 2004). Spatial and temporal patterns of vegetation regulate the exchange of mass, energy and momentum across the biosphere-atmosphere interface. To foster the understanding of natural phenomena caused by meteorological anomalies and modified by various land surface features (e.g. floods, drought), the ecosystems' energy and water balances are of primary importance as the main driving processes.

In our work, multiple equilibrium states in the soilvegetation-atmosphere system are characterised by the different levels of soil moisture availability that varied between the possible minimum and maximum values (permanent wilting point and field capacity), depending on soil physics, degree of moisture access to plants and available precipitations a day before. Based on the SVAT model SM output data, an Index designating Soil Moisture Availability /SMA/ in the root zone has been developed. This Index is designed as a 6-level threshold scheme to account for moistening conditions of: 'Drought', 'Drought risk', 'Dry', 'Optimum', 'Wet', 'Soaking wet'. The moistening conditions characterised by the SMA Index are visualized by colour-coded maps covering the main administrative regions of Bulgaria (see Fig.1). It is used as a diagnostic tool in support to issuing warnings for land surface conditions favourable for extreme over-moistening and flash floods (drought/fire environment). 
In the current work, we focus on using SMAI threshold scheme in the context of analyses and forecast of deep convection and flood risk evaluation.

\section{INFLUENCE OF SOIL MOISTURE ON CONVECTIVE PRECIPITATIONS}

Coupling between soil moisture and convective rainfall involves a large number of interacting processes occurring within the soil-plant-atmosphere system that vary over a wide range of space and time scales and complicates the problem. As reviewed by Iwasky and Fujii (2011), mesoscale variations in the SM content and land use yield differential heating. If the synoptic-scale forcing is weak, this differential heating induces secondary local circulation and local evapotranspiration, which plays a critical role in developing horizontal moisture flux convergence, destabilizing the local air mass and may produce shallow convective clouds and precipitation.

Hauck et al. (2011) conducted sensitivity studies by using artificially decreased/increased SM values as initial conditions in operational and high-resolution numerical simulations with a weather forecasting system to analyse the discrepancies between observed and modelled SM fields and their potential impacts on convective precipitation forecasts. The reduced SM did tend to facilitate convection initiation, as the convective temperature (necessary to release the convective available potential energy (CAPE) by buoyancy) was reached more easily for drier soil surfaces. As a further potential influence of SM, the timing of convection initiation at the surface is dependent on how fast the surface temperature can reach the convective temperature, both being dependent on the near-surface SM.

The sensitivity experiments performed (Hauck et al., 2011) showed that wet soil conditions in the numerical model lead to moister and cooler boundary layers as well as lowered lifting condensation levels and levels of free convection, facilitating the development of deep convection. In particular, the interplay between CAPE, which may depend strongly on surface fluxes, and convective inhibition (CIN), being more dependent on upper-level processes, plays a major role in the impact of SM in complex terrain. However, for most mid-tropospheric forcing cases of convection, the SM plays no (or only a very minor) role, because the humidity in the PBL (which strongly influences the above-mentioned variables) is advected from upstream and does not depend on the soil characteristics.

Studies on the influence of SM on deep convection over an arid environment in Mongolia based on volumetric SM satellite data and estimation of convective activity by Cband radar have been performed (Iwasky and Fujii, 2011). It was found that: SM averaged over the analysis region was strongly influenced by the variations in the precipitation amount; Onset of deep convection (DC) and the peak of convective activity were delayed for $1-2 \mathrm{~h}$ on moist soil days as compared to those on dry soil days. DC tended to develop over an area with positive anomalies of SM under dry SM conditions. DC could occur even for relatively low instability on dry soil days, whereas high instability was necessary for its occurrence on the moist soil days.

\section{USE OF SVAT SOIL MOISTURE PRODUCTS IN SUPPORT TO OPERATIONAL CONVECTIVE WEATHER FORECAST}

The results recently presented in the literature confirmed that the relationship between soil moisture distribution and convective activity is quite complex, strongly dependent on the synoptic-scale pattern and far from being well understood. Quantification of the SM impact in operational NWP modelling of convective precipitation is still inadequate, one of the potential uncertainties being the influence of soil conditions, such as SM and/or soil texture, and their relative importance in different regions (Hauck et al., 2011). Concerning with this, the approach adopted in our framework is quantitative evaluating of land surface moistening by daily run of a SVAT model and its operational use as additional to the NWP information for qualitative analyses/forecasts of convection. Using this methodology, investigations of strong convective events over Bulgaria for the period 2010-2011 and possibility for evaluation of over moistening and flood risk are performed.

Two case studies of severe weather events over the North-Western (NW) part of Bulgaria developed at strong large-scale forcing and different land surface moist conditions are presented as examples. They illustrate the methodology, which is used for assessing how the synoptic scale pattern (analysed by NWP, satellite and other observational data) interacts with the SM pattern to influence the occurrence of different type of severe weather.

Case 1: Low risk of flood. Deep convection in dry low-level tropospheric environment. A severe weather situation with damages of houses, rooted out trees and interrupted electric power /Bulgaria, Kneza, 20 July 2011/.

The synoptic analyses reveals that the process developed at strong upper-level forcing of convection through vorticity advection in the leading diffluent part of the upper-level PV anomaly. Fig. 1 shows the water vapour (WV) channel image overlaid by the heights of the surface of constant potential vorticity (PV) equal to 1.5 PV-units near the time of maximum development of severe convection over the NW part of Bulgaria (at the red arrow). The vertical profile by ARPEGE NWP model valid for 15 UTC (Fig. 2) as well as by the upper-air sounding in Sofia release point (about $150 \mathrm{~km}$ to the southwest, not presented) at 12 UTC, show very low humidity at low-levels (dew point depression: $20^{\circ}$ at $900 \mathrm{hPa}, 13^{\circ}$ at $850 \mathrm{hPa}, 4^{\circ}$ at $700 \mathrm{hPa}$ ). There are also ARPEGE model derived strong instability with a CAPE of $2180 \mathrm{~J} / \mathrm{kg}$ and warm advection from 850 to $600 \mathrm{hPa}$ (right wind shear). The strong wind shear from the surface to $600 \mathrm{hPa}$ and strong increase of wind speed aloft are conditions favourable for wind gust and tornado related to the convective system.

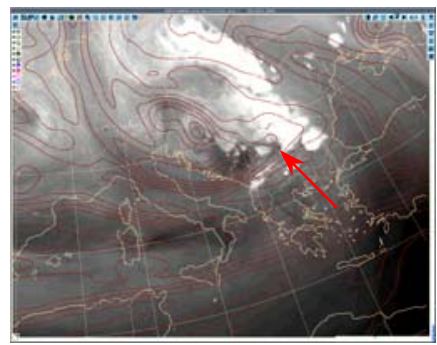

FIG. 1: Meteosat-9 WV image for 20 July 20111400 UTC superimposed by 3h ARPEGE forecast of heights of constant PV surface 1.5 PV-units.

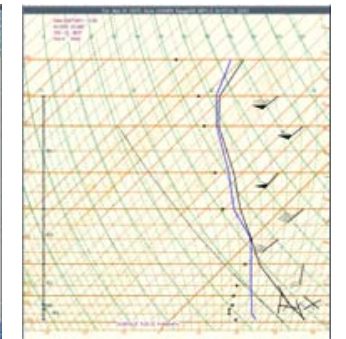

FIG. 2: Vertical profile by ARPEGE NWP model near the severe convective event 20 July 1500 UTC.
Land surface analyses of moistening conditions in the NW Bulgaria (Fig. 3a) show predominantly limited soil moistening (yellow to red colours) and close to the lower limit of optimal (green colour with around $50 \mathrm{~mm}$ precipitation needed to cause over moistening). These 
mostly dry SM conditions mean small impact of low-level moistening through evapotranspiration from the vegetation land cover. In this case, the thermal forcing plays an important role and the first convective clouds at western part of Bulgaria started to develop around $15 \mathrm{~h}$ local time. The precipitation quantities indicated on Fig. 3a show that according to the SVAT model simulations, rain of 46 to 79 $\mathrm{mm}$ is needed to cause flood risk in NW part of Bulgaria.

(a)

(b)

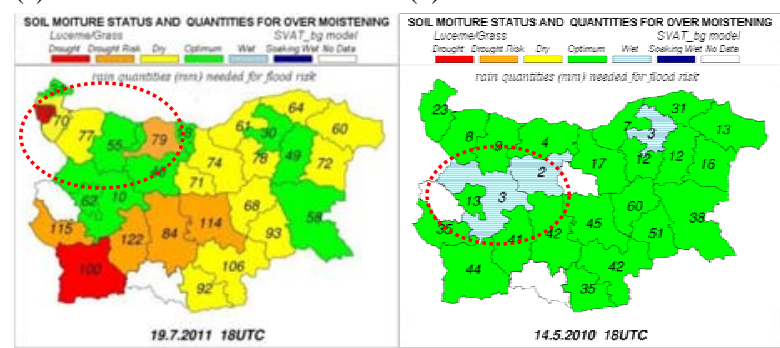

FIG. 3: 'SVAT_bg' model analysis of SM availability over Bulgaria and rain quantities $(\mathrm{mm})$ needed for flood risk at 1800 UTC on (a) 19 July 2011 and (b) 14 May 2010. The regions of interest are indicated by the dashed ellipses.

According to the operational forecast, Orange Code of MeteoAlarm for thunderstorms with showers and hail is predicted. There was no forecast for heavy rain and floods. The maximum precipitation measured among the synoptic stations in NW Bulgaria was $41 \mathrm{~mm}$ that was lower than the required quantities for over moistening according the SMA Index for the region of interest (see Fig. 3a). The severity of this case was due to damaging wind and floods were not produced.

Case 2: High risk of flood. Kata-cold front. Convective precipitation caused flood damages over NWBulgaria /Bulgaria, Dragoman, 15 -16 May 2010/.

In contrast to the Case 1, the map of soil moistening (Fig. 3b) over the studied region shows that SM is too high and only 2 to $10 \mathrm{~mm}$ rain is needed to cause over moistening and risk of flood in NW part of Bulgaria. At the same time polar cyclogenesis occurs over the region with fast deepening of $6 \mathrm{hPa}$ for 6 hours on 15 May 2010 that was associated with kata surface cold front (SCF). In such situations intensive precipitations are possible at the upper cold front (UCF) where the cloudiness develops abruptly and often convectively. The strong dry intrusion in the rear side of the cyclone is seen in the WV image (fig. 4a) that is associated with a PV anomaly and a jet at upper level (see Georgiev and Santurette, 2005), and produces potential instability and convection at the kata-cold front near the low centre.

(a)

(b)

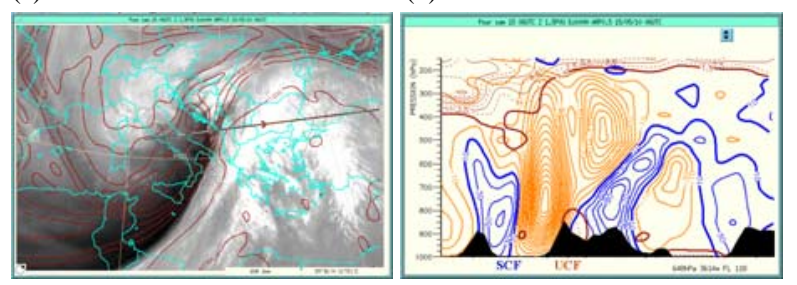

FIG. 4: (a) Meteosat-9 WV image for 15 May 20100600 UTC superimposed by ARPEGE analysis of heights (brown) of the 1.5 PV-units surface. (b) Vertical cross-section along black line in (a) of $\mathrm{PV}$ (brown, only $>1.5 \mathrm{PV}$-units and vertical velocity $\left(\left[10^{-2} \mathrm{~Pa} / \mathrm{s}\right]\right.$, ascending in orange, descending in blue). The relief is shown in black.

The vertical cross section on Fig. 4b shows a complex distribution of the vertical velocity produced by the tropospheric dynamics and orography. At the areas of lowlevel descending motion below the UCF, the evaporation from the vegetation is not a factor for moisture supply in the troposphere although the soil moisture content is high. In this case the SVAT model derived SMA Index map (Fig. 3b) can tell us that SM conditions are favourable for occurrence of a flash flood event. The maximum precipitation measured among the synoptic stations in NW Bulgaria was $43.1 \mathrm{~mm}$, which is close to that in Case 1, but much higher initial SM was the additional critical factor that caused the reported flash-flood in the Western regions of Bulgaria on 15-16 May 2010.

The soil moisture and soil moisture gradient values play a significant role in convection initiation and may serve as an early warning condition of flood risk under certain synoptic types. Further examination of these relations is needed regarding the role of soil moisture under a variety of synoptic regimes.

\section{ACKNOWLEDGMENTS}

Visualization of colour-coded maps of land surface moistening at NIMH over the target region is performed by Dr. P. Neichev.

\section{REFERENCES}

Baudena M., D'Andrea F., Provenzale A., 2008: A model for soil-vegetation-atmosphere interactions in water-limited ecosystems. Water Resour. Res., 44, W12429.

Claussen M. (Ed.), 2004: Does land surface matter in climate and weather? In: Vegetation, Water, Humans and the Climate, vol. Part A, edited by. P. Kabat et al. pp. 5153, Springer-Verlag, Heidelberg.

nitiation along soil moisture boundaries in the southern Great Plains. Mon. Weather Rev., 124, 1786-1802.

Hauck C., Barthlott C., Krauss L, Kalthoff N,. 2011: Soil moisture variability and its influence on convective precipitation over complex terrain. Q. J. R. Meteorol. Soc. 137: 42-56. DOI:10.1002/qj.766.

Iwasky H., Fujii H., 2011: A study of the influence of soil moisture on deep convection around Ulaambaatar, Mongolia, as an arid environment using AMSR-E Soil Moisture. J. Meteorol. Soc. Japan,. 89A: 97-109.

Le Lay M., Saulnier G. M., 2007: Exploring the signature of climate and landscape spatial variabilities in flash flood events: Case of the 8-9 September 2002 CévennesVivarais catastrophic event, Geophys. Res. Lett., 34, L13401.

Santurette P., Georgiev C. G., 2005: Weather Analysis and Forecasting: Applying Satellite Water Vapor Imagery and Potential Vorticity Analysis. ISBN: 0-12-619262-6. Academic Press. Copyright (C), Elsevier Inc. 179 pp.

Stoyanova J.S., Georgiev C.G., 2011: Monitoring and Analyses of the Vegetation Land Surface Status. Meteorological Applications. Bul J Meteo \& Hydro,16(1), 68-77.

Stoyanova J.S., Georgiev C.G., 2007: Interactions between the atmosphere and mountain forest: local scale assessment of energy and water fluxes. Proceedings of the 29th International Conference on Alpine Meteorology (ICAM), 04-08 June 2007, Chambéry, France, 729-732. 